\title{
The NiFe Hydrogenases of the Tetrachloroethene-Respiring Epsilonproteobacterium Sulfurospirillum multivorans: Biochemical Studies and Transcription Analysis
}

\author{
Stefan Kruse ${ }^{1 \dagger}$, Tobias Goris ${ }^{1 *}$, Maria Wolf1,2, Xi Wei ${ }^{1,3,4}$ and Gabriele Diekert ${ }^{1}$ \\ ' Department of Applied and Ecological Microbiology, Institute of Microbiology, Friedrich Schiller University, Germany, \\ ${ }^{2}$ Dianovis GmbH, Greiz, Germany, ${ }^{3}$ Department Isotope Biogeochemistry, Helmholtz Centre for Environmental \\ Research-UFZ, Leipzig, Germany, ${ }^{4}$ YMC Europe GmbH, Dinslaken, Germany
}

OPEN ACCESS

Edited by:

Inês A. Cardoso Pereira, Universidade Nova de Lisboa, Portugal

Reviewed by: Frank Sargent, University of Dundee, UK

Marianne Guiral,

Centre National de la Recherche

Scientifique (CNRS), France

${ }^{*}$ Correspondence:

Tobias Goris

tobias.goris@uni-jena.de

${ }^{\dagger}$ These authors have contributed equally to this work.

Specialty section:

This article was submitted to Microbial Physiology and Metabolism, a section of the journal

Frontiers in Microbiology

Received: 30 January 2017 Accepted: 03 March 2017 Published: 20 March 2017

Citation:

Kruse S, Goris T, Wolf M, Wei $X$ and Diekert G (2017) The NiFe Hydrogenases of the

Tetrachloroethene-Respiring Epsilonproteobacterium

Sulfurospirillum multivorans: Biochemical Studies and Transcription Analysis. Front. Microbiol. 8:444 doi: 10.3389/fmicb.2017.00444
The organohalide-respiring Epsilonproteobacterium Sulfurospirillum multivorans is able to grow with hydrogen as electron donor and with tetrachloroethene (PCE) as electron acceptor; PCE is reductively dechlorinated to cis-1,2-dichloroethene. Recently, a genomic survey revealed the presence of four gene clusters encoding $\mathrm{NiFe}$ hydrogenases in its genome, one of which is presumably periplasmic and membranebound $(\mathrm{MBH})$, whereas the remaining three are cytoplasmic. To explore the role and regulation of the four hydrogenases, quantitative real-time PCR and biochemical studies were performed with S. multivorans cells grown under different growth conditions. The large subunit genes of the $\mathrm{MBH}$ and of a cytoplasmic group 4 hydrogenase, which is assumed to be membrane-associated, show high transcript levels under nearly all growth conditions tested, pointing toward a constitutive expression in S. multivorans. The gene transcripts encoding the large subunits of the other two hydrogenases were either not detected at all or only present at very low amounts. The presence of $\mathrm{MBH}$ under all growth conditions tested, even with oxygen as electron acceptor under microoxic conditions, indicates that $\mathrm{MBH}$ gene transcription is not regulated in contrast to other facultative hydrogen-oxidizing bacteria. The $\mathrm{MBH}$ showed quinone-reactivity and a characteristic UVNIS spectrum implying a cytochrome $b$ as membrane-integral subunit. Cell extracts of $S$. multivorans were subjected to native polyacrylamide gel electrophoresis (PAGE) and hydrogen oxidizing activity was tested by native staining. Only one band was detected at about $270 \mathrm{kDa}$ in the particulate fraction of the extracts, indicating that there is only one hydrogen-oxidizing enzyme present in S. multivorans. An enrichment of this enzyme and SDS PAGE revealed a subunit composition corresponding to that of the $\mathrm{MBH}$. From these findings we conclude that the $\mathrm{MBH}$ is the electron-donating enzyme system in the PCE respiratory chain. The roles for the other three hydrogenases remain unproven. The group 4 hydrogenase might be involved in hydrogen production upon fermentative growth.

Keywords: organohalide respiration, hydrogenase, real-time PCR, regulation of gene expression, hydrogen, anaerobic respiration 


\section{INTRODUCTION}

Molecular hydrogen $\left(\mathrm{H}_{2}\right)$ is one of the primary electron donors for many anaerobic respiratory processes mediated by prokaryotes. Organohalide respiration, in which energy conservation is coupled to the reductive dehalogenation of halogenated organic compounds, is no exception in this regard. Obligate organohalide-respiring bacteria such as Dehalococcoides mccartyi and Dehalobacter restrictus rely solely on $\mathrm{H}_{2}$ as electron donor (Holliger et al., 1998; Löffler et al., 2013), while most versatile organohalide-respiring organisms, e.g., Desulfitobacterium spp. or Sulfurospirillum spp., use $\mathrm{H}_{2}$ as one of many electron donors (Scholz-Muramatsu et al., 1995; Luijten et al., 2003; Villemur et al., 2006; Goris and Diekert, 2016). One feature, which is common to many genomes of organohaliderespiring bacteria, is the presence of multiple hydrogenaseencoding gene clusters (Kube et al., 2005; Seshadri et al., 2005; Nonaka et al., 2006; Kruse et al., 2013, 2015; Goris et al., 2014). Besides $\mathrm{H}_{2}$ oxidation in respiratory processes, which is usually mediated by a membrane-bound $\mathrm{NiFe}$ hydrogenase, several different cellular metabolic processes are thought to recruit the other hydrogenase enzymes for either $\mathrm{H}_{2}$ oxidation or $\mathrm{H}^{+}$reduction. The roles of these hydrogenases are unknown and under debate (Seshadri et al., 2005; Rupakula et al., 2013; Goris et al., 2014; Mansfeldt et al., 2014; Kruse et al., 2015). For example, cytoplasmic hydrogenases with an $\operatorname{NAD}(\mathrm{P})^{+}$ binding motif might be responsible for generating reducing equivalents for biosynthetic pathways or for balancing the cellular redox state. Group 4 Ech-type hydrogenases, which often harbor several large membrane-integral subunits, might also be involved in energy-conserving processes, as reported for methanogens (Hedderich and Forzi, 2005; Welte et al., 2010).

Sulfurospirillum multivorans is a versatile organohaliderespiring Epsilonproteobacterium that uses $\mathrm{H}_{2}$ or other compounds such as formate or pyruvate as electron donors and chlorinated ethenes or, e.g., nitrate or fumarate as electron acceptor (Scholz-Muramatsu et al., 1995; Goris and Diekert, 2016). Recently, it has also been shown that the organism is able to utilize $\mathrm{O}_{2}$ as terminal electron acceptor under microoxic conditions with about $5 \% \mathrm{O}_{2}$ in the gas phase (Goris et al., 2014). The genome of S. multivorans contains gene clusters encoding four different NiFe hydrogenases. One is predicted to be a periplasmic, membrane-bound $\mathrm{H}_{2}$-oxidizing enzyme (membrane-bound hydrogenase, $\mathrm{MBH}$, HydABC encoded by SMUL_1423-1425), which is very similar (50 to $76 \%$ subunit amino acid sequence identity) to the characterized uptake hydrogenase of Wolinella succinogenes (Dross et al., 1992). The small subunit of the MBH of both organisms, HydA, contains a TAT signal peptide which is cleaved off after maturation and transport of the $\mathrm{MBH}$ into the periplasm. HydC is a membrane-integral cytochrome $b$ subunit which connects the hydrogenase to the quinone pool (Gross et al., 2004). The other three hydrogenases contain no signal peptide motif and are therefore considered to be cytoplasmic (Goris et al., 2014). One of these three enzymes (HupSL, encoded by SMUL_14211422 ) is related to cytoplasmic $\mathrm{H}_{2}$-consuming hydrogenases and regulatory hydrogenases, the other two can be classified as group 4 hydrogenases, which are known to produce $\mathrm{H}_{2}$ (Vignais and Billoud, 2007). The hydrogenase encoded by the ech gene cluster (structural proteins EchEDFC encoded by SMUL_1307-1310) bears similarities to the CO-induced hydrogenase of Carboxydothermus hydrogenoformans (Soboh et al., 2002), but the S. multivorans genome does not contain genes coding for a $\mathrm{CO}$ dehydrogenase. Hydrogenase membrane subunit genes were not found on the ech gene cluster, which is remarkable, since all group 4 hydrogenase gene clusters normally contain genes encoding membrane-integral subunits (Greening et al., 2016). The fourth hydrogenase comprises eight subunits (HyfABCEFGHI encoded by SMUL_2383-2390), of which four are predicted to be membrane-integral. This hydrogenase is similar to hydrogenase 4 (Hyf) of Escherichia coli. This enzyme found in several Enterobacteriaceae might interact with a cytoplasmic formate dehydrogenase (FdhF) to form a formate hydrogen lyase (FHL) complex (Trchounian et al., 2012; Sargent, 2016). At least two of the hydrogenases of S. multivorans, the $\mathrm{MBH}$ and the Hyf, are produced during tetrachloroethene (PCE) respiration with either pyruvate or formate as sole electron donor (Goris et al., 2015). The periplasmically oriented $\mathrm{MBH}$ is assumed to be the main $\mathrm{H}_{2}$ oxidizing enzyme in $\mathrm{S}$. multivorans, since $\mathrm{H}_{2}$-oxidizing activity was detected in whole cells and the majority of this activity was found to be membrane-associated (Miller et al., 1996). However, these assays were performed with cells and extracts from S. multivorans grown with $\mathrm{H}_{2} /$ fumarate, while a study with $\mathrm{H}_{2} / \mathrm{PCE}$-grown cells was never carried out. Deduced from amino acid sequence similarity, HupSL was discussed to play a role in either the recycling of $\mathrm{H}_{2}$ produced cytoplasmically (e.g., during $\mathrm{N}_{2}$ fixation) or to deliver low-potential reducing equivalents for anabolic purposes comparable to Aquifex aeolicus hydrogenase III (Guiral et al., 2005). However, it could also be involved in $\mathrm{H}_{2}$-dependent $\mathrm{PCE}$ respiration. The two group 4 hydrogenases might play a role in $\mathrm{H}_{2}$ production from excess reducing equivalents during fermentative growth. The putative roles of the four hydrogenases in S. multivorans are depicted in Figure 1.

Usually hydrogenase expression underlies specific regulation depending on their physiological role and growth conditions (Kovács et al., 2005; Greening and Cook, 2014). For example, uptake hydrogenases gene transcription is upregulated when $\mathrm{H}_{2}$ is available, NiFe hydrogenase gene expression is down-regulated when the cofactor nickel is absent, and $\mathrm{O}_{2}$-sensitive hydrogenases are not expressed under oxic conditions. However, in both Epsilonproteobacteria and organohalide-respiring bacteria nearly nothing is known about hydrogenase gene regulation. In this study we wanted to (1) reveal the hydrogen uptake metabolism of S. multivorans during $\mathrm{H}_{2}$-driven PCE respiration and characterize the uptake hydrogenase involved in this process and (2) investigate the transcript profiles of hydrogenase catalytic subunit genes during different growth conditions, which might give information about the regulation of the four hydrogenases and their physiological role in S. multivorans. 


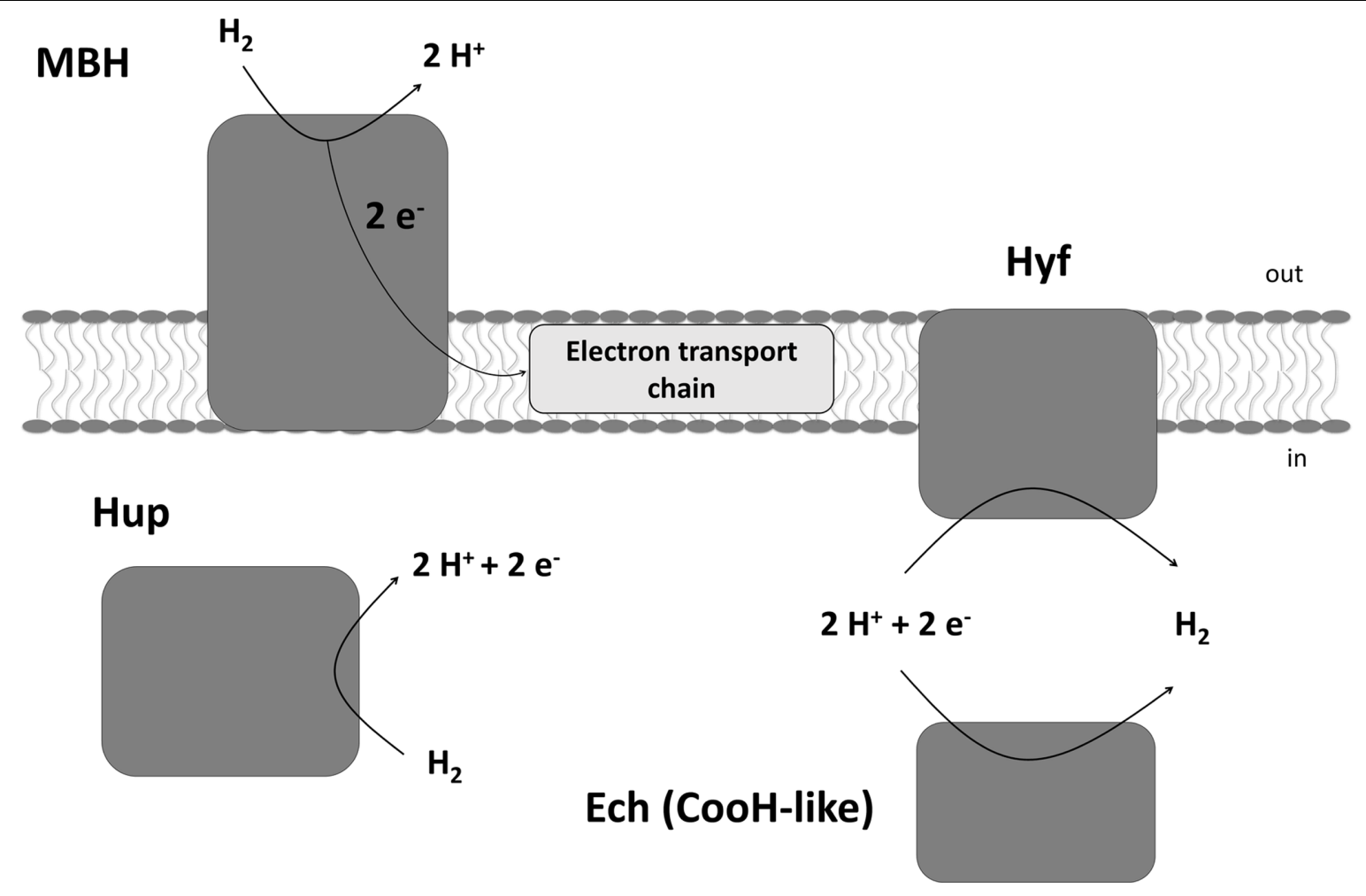

FIGURE 1 | Putative physiological roles of the four hydrogenases of Sulfurospirillum multivorans and their subcellular localization. MBH, membrane-bound hydrogenase HydABC; Hup, cytoplasmic uptake hydrogenase HupSL; Hyf, HyfABCEFGHI similar to E. coli hydrogenase 4; Ech, EchEDFC, similar to the CO-induced hydrogenase of Carboxydothermus hydrogenoformans, but in S. multivorans lacking any membrane subunit.

\section{EXPERIMENTAL PROCEDURES}

\section{Cultivation of S. multivorans}

Sulfurospirillum multivorans (DSMZ 12446) was grown anaerobically at $28^{\circ} \mathrm{C}$ in rubber stoppered glass bottles shaken at $150 \mathrm{rpm}$ with an aqueous to gas phase ratio of 1:1. The medium was described previously containing cysteine as reductant but did not contain vitamin $\mathrm{B}_{12}$ (cyanocobalamin) here (ScholzMuramatsu et al., 1995). Before autoclaving, the gas phase contained $150 \mathrm{kPa} \mathrm{N} 2$. Pyruvate $(40 \mathrm{mM})$ was used as electron donor and fumarate $(40 \mathrm{mM}), \mathrm{PCE}$, nitrate $(10 \mathrm{mM})$, or $5 \% \mathrm{O}_{2}$ as electron acceptor. In the latter case, $\mathrm{O}_{2}$ concentration in the gas phase was measured with the Microx 4 oxygen meter (PreSens Precision Sensing GmbH, Regensburg, Germany). The amount of $5 \% \mathrm{O}_{2}$ in the gas phase corresponded to approximately $0.5 \mathrm{mg} / \mathrm{L}$ medium in the liquid phase. Cells growing with pyruvate as electron donor were cultivated at least 50 transfers without $\mathrm{H}_{2}$ in the gas phase to test for possible long-term regulation effects. PCE was added to the medium in a nominal concentration of $10 \mathrm{mM}$ from a $0.5 \mathrm{M}$ PCE hexadecane stock solution. When cells were cultivated with $\mathrm{H}_{2}$ as electron donor, a gas phase of $\mathrm{H}_{2}(150 \mathrm{kPa})$ was applied and acetate $(5 \mathrm{mM})$ was added as carbon source. For experiments with $\mathrm{N}_{2}$ as sole nitrogen source, ammonium chloride was omitted from the basal medium and $\mathrm{N}_{2}$ $(150 \mathrm{kPa})$ was used as gas phase. The following energy substrate combinations were used: pyruvate/fumarate, pyruvate/PCE, pyruvate $/ \mathrm{O}_{2}$, pyruvate alone, $\mathrm{H}_{2} / \mathrm{PCE}$, and $\mathrm{H}_{2} /$ nitrate. Growth was monitored photometrically at $578 \mathrm{~nm}$.

\section{Cell Harvesting and Samples Preparation}

Sulfurospirillum multivorans cells were harvested oxically in the mid-exponential growth phase by centrifugation $(12,000 \times g$, $10 \mathrm{~min}$ at $10^{\circ} \mathrm{C}$ ). Resulting cell pellets were washed twice in $50 \mathrm{mM}$ Tris- $\mathrm{HCl}(\mathrm{pH}$ 7.5) and resuspended in two volumes (2 $\mathrm{ml}$ per $\mathrm{g}$ cells) of the same buffer with additional DNase I (AppliChem, Darmstadt, Germany) and protease inhibitor (one tablet for $10 \mathrm{ml}$ buffer; cOmplete Mini, EDTA-free; Roche, Mannheim, Germany). Cell disruption was carried out semianoxically using a French Press cell (1500 psi), which was made anoxic in a glovebox (Coy Laboratory Products Inc., Grass Lake, MI, USA), while the disruption itself was performed outside the tent. The obtained crude extracts were used for biochemical experiments. Cells were fractionated by ultracentrifugation $\left(36,000 \times g, 45 \mathrm{~min}\right.$ at $\left.4^{\circ} \mathrm{C}\right)$, supernatants were designated soluble fractions (SF). The pellets were resuspended in two volumes ( $2 \mathrm{ml}$ per g membrane pellet) $50 \mathrm{mM}$ Tris- $\mathrm{HCl}(\mathrm{pH} 7.5)$; a part of this suspension was used further as membrane fraction (MF), while the rest was mixed with $0.1 \%$ Triton $\mathrm{X}-100$ and stirred at $4^{\circ} \mathrm{C}$ overnight. Solubilized membrane extract (ME) was obtained from the resulting supernatant after ultracentrifugation $\left(36,000 \times g, 45 \mathrm{~min}\right.$ at $\left.4^{\circ} \mathrm{C}\right)$. 


\section{Enrichment of the Membrane-Bound Hydrogenase}

Enrichment was carried out at room temperature in an anoxic chamber with an atmosphere of $98 \% \mathrm{~N}_{2}$ and $2 \%$ $\mathrm{H}_{2}$ (Coy Laboratory Products Inc., Grass Lake, MI, USA) using an ÄKTA-FPLC system (GE Healthcare Europe GmbH, Freiburg, Germany). Cells were grown in $2 \mathrm{~L}$ Schott bottles (aqueous to gas phase ratio 1:1) with pyruvate and fumarate. Harvesting, disruption and fractionation was done as described in the previous chapter, except that $1 \%$ digitonin was used as detergent. The filtered solubilized $\mathrm{ME}$ was fractionated via an anion exchange column (Q-Sepharose HP column 10/10, GE Healthcare Europe GmbH, Freiburg, Germany). The Q-Sepharose column was pre-equilibrated with $50 \mathrm{mM}$ Tris- $\mathrm{HCl}(\mathrm{pH} 8.0), 0.5 \mathrm{mM}$ DTT and $0.1 \%(\mathrm{v} / \mathrm{v})$ Triton X100. Subsequently, the column was washed with $200 \mathrm{ml}$ of the same buffer. Elution of proteins was achieved with a linear salt gradient from 0 to $0.5 \mathrm{M} \mathrm{KCl}$ at a flow rate of $2 \mathrm{ml} / \mathrm{min}$. Fractions containing hydrogenase activity eluted at approximately $0.2 \mathrm{M} \mathrm{KCl} . \mathrm{H}_{2}$-oxidizing activity was checked photometrically and by activity stained blue native $(\mathrm{BN})$ polyacrylamide gel electrophoresis (PAGE), while purity was checked by SDS PAGE and silver-stained BN PAGE.

\section{Blue Native Gel Activity Staining PAGE and SDS PAGE}

Non-denaturing PAGE was performed with native gels from SERVA (SERVAGEL N, Heidelberg, Germany). The anaerobic running buffer system was composed of a cathode buffer $(50 \mathrm{mM}$ Tricine, $15 \mathrm{mM}$ BisTris-HCl, $1 \mathrm{ml} / \mathrm{L}$ Serva Blue G; pH 7.0) and anode buffer (15 mM BisTris-HCl; pH 7.0). Samples were mixed with twofold loading dye (1 M 6-Aminocaproic acid; $100 \mathrm{mM}$ BisTris- $\mathrm{HCl} \mathrm{pH} 7.0 ; 100 \mathrm{mM} \mathrm{NaCl} ; 20 \%$ glycerol; $0.1 \%$ Serva Blue G250). The protein marker used was a SERVA Native Marker Liquid Mix. The gels were run in a vertical polyacrylamide electrophoresis system (Minigel-Twin, Biometra $\mathrm{GmbH}$, Göttingen, Germany) starting with $50 \mathrm{~V}$ for $10 \mathrm{~min}$ and subsequently $200 \mathrm{~V}$ for about $2 \mathrm{~h}$. The gel electrophoresis was performed in an anoxic glovebox (Coy Laboratory Products Inc., Grass Lake, MI, USA). $\mathrm{H}_{2}$-oxidizing activity was visualized as follows: The gel was transferred to an anoxic Schott bottle filled with $50 \mathrm{mM}$ Tris- $\mathrm{HCl}$ ( $\mathrm{pH}$ 8.0) buffer containing $1 \mathrm{mM}$ benzyl viologen (BV) as primary electron acceptor and redox mediator and $1 \mathrm{mM}$ triphenyl tetrazolium chloride (TTC) as terminal electron acceptor for permanent staining. The bottle was then flushed with pure $\mathrm{H}_{2}$ for $30 \mathrm{~min}$. The incubation was carried out in a $28^{\circ} \mathrm{C}$ water bath until first bands were visible and then stopped by removing the native gel from the bottle. Fractions obtained from enrichment procedure were subjected to SDS-PAGE, which was silver stained after the run.

\section{Photometric Measurement of Hydrogenase Activity}

$\mathrm{H}_{2}$-oxidizing activity was measured spectrophotometrically in butyl rubber stoppered glass cuvettes filled with $1 \mathrm{ml} \mathrm{H}_{2}$ saturated buffer ( $50 \mathrm{mM}$ Tris- $\mathrm{HCl}, \mathrm{pH} 8.0$ ) made anoxic by flushing with $\mathrm{H}_{2}$ for $5 \mathrm{~min}$. Redox dyes used were $1 \mathrm{mM}$ benzyl viologen (BV), $1 \mathrm{mM}$ methyl viologen (MV), or $1 \mathrm{mM}$ methylene blue $(\mathrm{MB})$ at $30^{\circ} \mathrm{C}$. The colorization caused by the reduction of $\mathrm{BV}$ or MV was recorded at $578 \mathrm{~nm}$ and decolorization of $\mathrm{MB}$ was monitored at $570 \mathrm{~nm}$. Additionally, activity was measured with the menaquinone analogs 1,4-naphthoquinone and 2,3dimethyl-1,4-naphthoquinone (DMN). Changes in absorption during reduction of these derivatives were recorded at $270 \mathrm{~nm}$. The anoxic reaction buffer contained $0.2 \mathrm{mM}$ DMN or 1,4naphthoquinone in $50 \mathrm{mM}$ glycylglycine $(\mathrm{pH} 8.0)$ and $0.5 \mathrm{mM}$ DTT. The assay was performed in rubber-stoppered quartz cuvettes, flushed with $\mathrm{H}_{2}$. Reduction of DMN was recorded using the absorbance difference at 270 and $290 \mathrm{~nm}$. Determination of protein concentration was done according to the method of Bradford (1976). Activity values are given in nanokatal (oxidation of $1 \mathrm{nmol} \mathrm{H}_{2}$ per second). Temperature and $\mathrm{pH}$ dependance was measured with enriched hydrogenase using a $50 \mathrm{mM}$ BrittonRobinson buffer system $\left(50 \mathrm{mM} \mathrm{H}_{3} \mathrm{BO}_{3}, 50 \mathrm{mM} \mathrm{H}_{3} \mathrm{PO}_{4}, 50 \mathrm{mM}\right.$ acetate) in a $\mathrm{pH}$ range from 5.5 to 10 and a temperature range between 10 and $50^{\circ} \mathrm{C}$.

\section{Isolation of RNA, Reverse Transcription, and Quantitative Real-Time PCR}

Isolation of total RNA from S. multivorans was done using the RNeasy minikit (Qiagen, Hilden, Germany). Remaining genomic DNA was removed with DNase I (RNase free; Roche, Mannheim, Germany). For quality check of the RNA, agarose gel electrophoresis was performed. For all quantitative real-time PCR (qPCR) experiments, the RNA was isolated in the midexponential growth phase of three independently grown cultures. For cDNA synthesis, $1 \mu \mathrm{g}$ of RNA was used as starting material in the RevertAid First Strand cDNA Synthesis kit (Thermo Scientific, Schwerte, Germany). The reaction mixture contained $1 \mu \mathrm{g}$ RNA, $2.5 \mu \mathrm{l}$ reverse primer, $3.5 \mu \mathrm{l} 5 \mathrm{x}$ reaction buffer, and $2 \mu \mathrm{l} 10 \mathrm{mM}$ dNTP mix. It was filled up to a final volume of $17.5 \mu \mathrm{l}$ with PCR-grade water (Fermentas, St. Leon Rot, Germany). To $10.5 \mu \mathrm{l}$ of the mix, $0.5 \mu \mathrm{l}$ RevertAid Reverse transcriptase (RT; $200 \mathrm{U} / \mu \mathrm{l}$ ) was added, the residual amount (mix without RT) was used as negative control. The mix was incubated for $1 \mathrm{~h}$ at $42^{\circ} \mathrm{C}$ in a thermo cycler (Mastercycler, Personal, Eppendorf, Hamburg, Germany) and the reaction was stopped at $72^{\circ} \mathrm{C}$ for $5 \mathrm{~min}$. Transcript levels of the different genes were compared by qPCR with the Maxima SYBR green qPCR master mix (Fermentas, St. Leon Rot, Germany); the primer pairs used are listed in Supplementary Table 1 . The assay was performed in triplicates in a CFX96 qPCR machine (Bio-Rad, Munich, Germany). The PCR reaction mixture included $2.5 \mu \mathrm{l}$ cDNA, $0.5 \mu \mathrm{M}$ of each primer, and $6 \mu \mathrm{l} 2 \mathrm{x}$ Maxima SYBR green $\mathrm{qPCR}$ master mix and was filled up to a final volume of $12 \mu \mathrm{l}$ with PCR-grade water. Two negative controls were used, one with water as $\mathrm{qPCR}$ template and a reverse transcriptase negative control for each tested gene. Melting curve analysis was performed to exclude the formation of primer dimers or unspecific byproducts. Before performing the $\mathrm{qPCR}$ experiments, primer efficiency was tested for all primer pairs used in this study to ensure accurate and comparable amplification (see Supplementary Data Sheet 2). Three different control genes for normalization were tested: $16 \mathrm{~S}$ 
rRNA, recA, rpoB. Only the first was useful as control gene under all growth conditions applied. Obtained data were thus normalized to $16 \mathrm{~S} \mathrm{cDNA}$ (diluted 1:10,000) and the calculation of the relative gene expression level was done according to the $2^{-\Delta \Delta C T}$ method (Schmittgen and Livak, 2008), except where stated otherwise. For statistical analysis, student's $t$-test was performed on the ${ }^{\Delta \mathrm{CT}}$-values; $p$-values lower than 0.05 were regarded as significant.

\section{RESULTS}

\section{Transcript Levels of Hydrogenase Genes under Different Growth Conditions}

To determine and compare the transcript levels of the hydrogenase genes under different growth conditions, S. multivorans was grown with the following substrate combinations: pyruvate plus fumarate (standard condition), PCE, $5 \% \mathrm{O}_{2}$, or without external electron acceptor, or $\mathrm{H}_{2}$ plus PCE or nitrate. In addition, $\mathrm{N}_{2}$-fixing conditions were achieved with $\mathrm{N}_{2}$ as sole nitrogen source. Prior to the main $\mathrm{qPCR}$ experiments, three housekeeping genes were tested for their suitability as reference genes: 16S rRNA, recA and $r p o B$. The latter was not considered further due to unspecific products and primer specificities out of an acceptable range (more than 10\% deviation from primer specificities for the other primer pairs). The $r e c A$ gene was unsuitable, since the transcript levels varied too much among replicates and under the different growth conditions (see Supplementary Data Sheet 2). Therefore, hydrogenase qPCR data were normalized to the 16S rRNA gene when comparing transcript levels under different growth conditions. For hydrogenase $\mathrm{qPCR}$, the following genes encoding the catalytic subunits of each hydrogenase gene cluster were chosen: hydB (SMUL_1424) of the $\mathrm{MBH}$ gene cluster, hupL (SMUL_1422) from the cytoplasmic uptake hydrogenase (hupSL), echE (SMUL_1307) from the CooH-like hydrogenase and hyfG (SMUL_2388) from the Hyf hydrogenase. Primers used in qPCR are listed in Supplementary Table 1.

Transcripts of only two hydrogenase genes, hydB and hyfG (large subunits of the $\mathrm{MBH}$ and of Hyf) were found at levels of 0.03 to 0.08 (after normalization to $16 \mathrm{~S}$ rRNA transcript level) under nearly all tested growth conditions. This was even the case when pyruvate rather than $\mathrm{H}_{2}$ was used as electron donor in cells cultivated for at least 50 transfers with pyruvate as sole energy source. A long-term transcriptional regulatory effect, as was seen for pceA (John et al., 2009), can therefore be excluded. Opposed to $h y d B$ and $h y f G$, hupL and echE transcripts were not detected under most conditions, except very low transcript levels under pyruvate/fumarate (below 0.001 , see Figure 2 and Supplementary Data Sheet 2). To establish the hydrogenases that are involved in $\mathrm{H}_{2}$-dependent PCE respiration, S. multivorans was grown in the presence of $100 \% \mathrm{H}_{2}$ in the gas phase as electron donor and $10 \mathrm{mM}$ PCE in a hexadecane phase as electron acceptor. Only an insignificant increase in $h y d B$ transcript level (about twofold, $p$-value 0.224 ) and a decrease of hyfG (about threefold, p-value 0.562) was observed (Figure 2). To compare these transcript levels to those of another anaerobic $\mathrm{H}_{2}$-dependent respiration, cells were grown with nitrate as electron acceptor and $\mathrm{H}_{2}$ as electron donor. Nitrate rather than fumarate was chosen as electron acceptor, since S. multivorans was shown to be capable of growth with fumarate alone by disproportionation (Scholz-Muramatsu et al., 1995). The hydB gene transcript level dropped slightly, but insignificantly compared to $\mathrm{H}_{2} / \mathrm{PCE}$ (twofold, $p$-value 0.384 ), while hyfG was reduced significantly in $\mathrm{H}_{2}$ /nitrate cells (about 30-fold lower; $p$-value 0.022) (Figure 2).

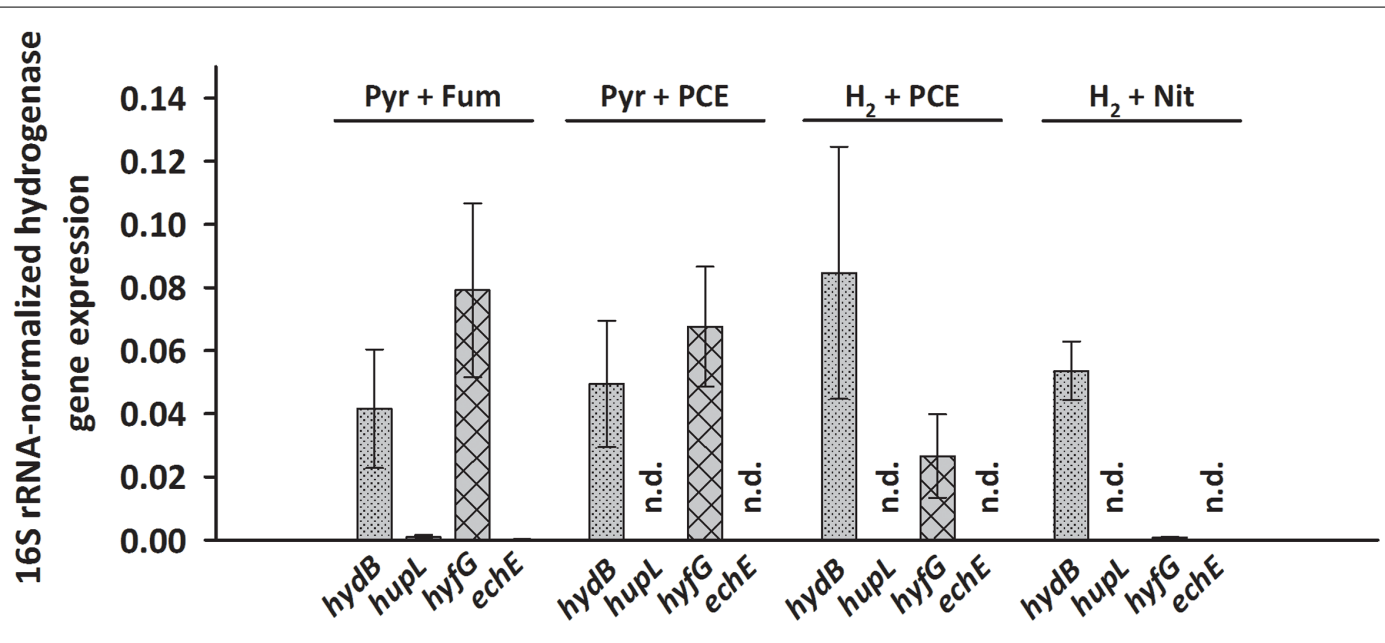

FIGURE 2 | Transcription pattern of hydrogenase catalytic subunit genes of S. multivorans grown under different growth conditions. Transcript levels of hydrogenase genes were normalized to those of the $16 \mathrm{~S}$ rRNA gene. All data were obtained from three biological replicates and three technical replicates. When amplification was detected only in one biological replicate, the hydrogenase gene was designated as not detected (n.d.). The raw data of all values are shown in the Supplementary Data Sheet 2. hydB, membrane-bound hydrogenase (MBH); hupL, cytoplasmic uptake hydrogenase; hyfG, Hyf-hydrogenase; echE, Ech-like hydrogenase. Pyr, pyruvate; Fum, fumarate; Nit, nitrate; PCE, tetrachloroethene. 


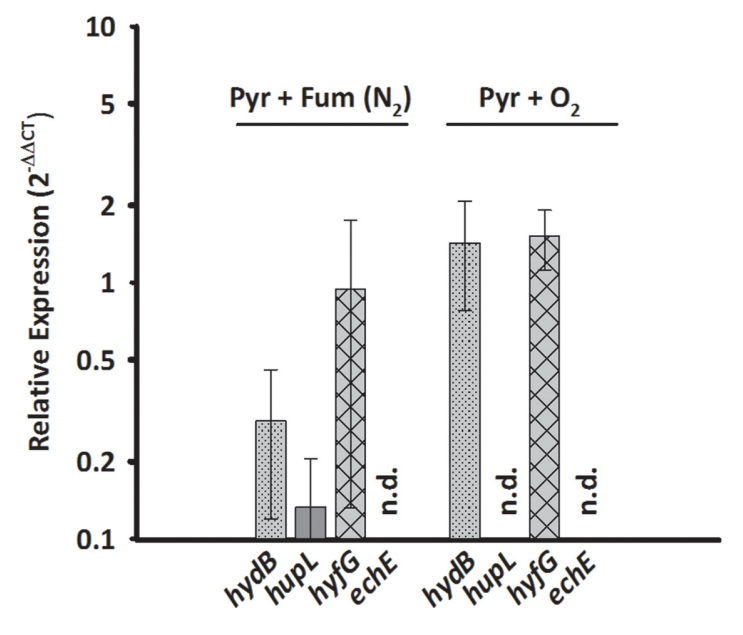

FIGURE 3 | Transcription pattern of hydrogenase catalytic subunit genes of $\mathrm{S}$. multivorans with $\mathrm{N}_{2}$ as sole $\mathrm{N}$-source and $5 \% \mathrm{O}_{2}$ as electron acceptor. Transcript levels obtained from cells grown with $\mathrm{N}_{2}$ as $\mathrm{N}$-source and $5 \% \mathrm{O}_{2}$ were normalized to the transcript levels of the corresponding hydrogenase genes of pyruvate/fumarate grown cells. All data were obtained from three biological replicates and three technical replicates. When amplification was detected only in one biological replicate, the hydrogenase gene was designated as not detected (n.d.). The raw data of all values are shown in the Supplementary Data Sheet 2 and Figure 1 shows the data normalized to $16 \mathrm{~S}$ rRNA gene. hydB, membrane-bound hydrogenase $(\mathrm{MBH})$; hupL, cytoplasmic uptake hydrogenase; hyfG, Hyf-hydrogenase; echE, Ech-like hydrogenase. Pyr, pyruvate; Fum, fumarate; $\mathrm{NH}_{4} \mathrm{Cl}$, with ammonium chloride; $\mathrm{N}_{2}, \mathrm{~N}_{2}$ as sole $\mathrm{N}$-source.

Since HupSL might be involved in recycling hydrogen produced during $\mathrm{N}_{2}$ fixation, as was shown for similar enzymes in cyanobacteria (Tamagnini et al., 2007; Bothe et al., 2010) and S. multivorans was shown to fix $\mathrm{N}_{2}$ (Ju et al., 2007; Goris et al., 2014), the transcript levels of hupL were investigated with $\mathrm{N}_{2}$ as sole $\mathrm{N}$-source. S. multivorans was grown under standard conditions (pyruvate/fumarate plus $\mathrm{NH}_{4} \mathrm{Cl}$ as $\mathrm{N}$-source) and with medium containing $\mathrm{N}_{2}$ as sole $\mathrm{N}$-source. The hupL transcript level did not increase with $\mathrm{N}_{2}$ as sole $\mathrm{N}$-source when compared to cells grown with $\mathrm{NH}_{4}{ }^{+}$. Instead, hupL and hydB levels decreased about 7.5- and 3-fold, albeit insignificantly with a $p$-value of 0.592 and 0.892 , respectively (Figure 3).

Aerobic growth of S. multivorans with pyruvate and an $\mathrm{O}_{2-}$ concentration of about $5 \%$ in the gas phase was described recently (Goris et al., 2014). Since NiFe hydrogenases are generally inactivated by $\mathrm{O}_{2}$ (Stiebritz and Reiher, 2012), it was of interest whether $\mathrm{O}_{2}$ could possibly cause a down-regulation of hydrogenase gene expression as found for other bacteria (Kovács et al., 2005). Therefore, qPCR of cells grown in the presence of $5 \% \mathrm{O}_{2}$ in the gas phase with pyruvate as electron donor was performed to test if hydrogenase transcription occurs in the presence of oxygen. Cells were harvested at an $\mathrm{O}_{2}$ concentration in the medium of at least $0.2 \mathrm{mg} / \mathrm{L}$. Surprisingly, the transcript levels of $h y d B$ and $h y f G$ were similar or insignificantly higher (about twofold for hydB, p-value of 0.553 ) under microoxic conditions compared to cells grown with fumarate as electron acceptor (Figure 3), while hupL and echE transcripts were not

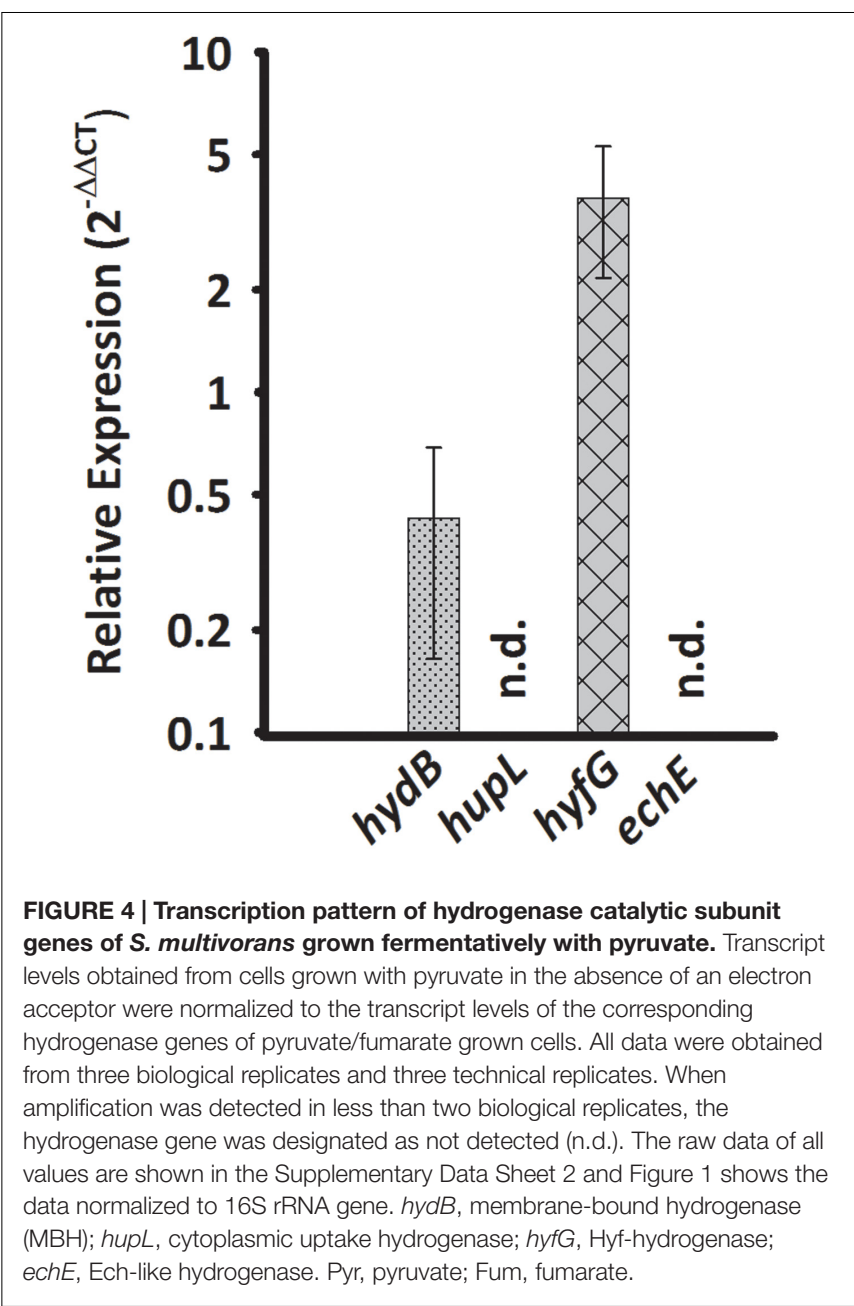

detected. The cells were, however, not able to grow with $\mathrm{H}_{2}$ as electron donor and $5 \% \mathrm{O}_{2}$ as electron acceptor and acetate as carbon source.

Sulfurospirillum multivorans was described to grow fermentatively with pyruvate as the sole energy source (ScholzMuramatsu et al., 1995). To investigate whether one of the putative $\mathrm{H}_{2}$-producing hydrogenases shows higher transcript levels under this growth condition, we compared qPCR results obtained from pyruvate-grown cells with those from pyruvate/fumarate-grown cells. The hydB transcript level was lowered insignificantly ( $p$-value 0.229 ) about threefold, while the hyfG level was increased by a factor of 3 with a $p$-value of 0.056 (Figure 4).

\section{Biochemical Characterization of the Membrane-Bound Hydrogenase}

To biochemically characterize the $\mathrm{H}_{2}$-oxidizing enzyme of cells grown under PCE-respiring conditions, we measured the $\mathrm{H}_{2}$ uptake activity of subcellular fractions from S. multivorans in different enzymatic assays. First, crude extracts of cells grown with pyruvate or $\mathrm{H}_{2}$ as electron donor and PCE as 
electron acceptor were tested spectrophotometrically for $\mathrm{H}_{2}$ oxidizing activity with several different artificial redox mediators as electron acceptors. The activity with BV was by far the highest and about five times higher than the activities with $\mathrm{MV}$ and approximately tenfold of the activity with $\mathrm{MB}$ (Figure 5A). The other redox mediators tested, $\mathrm{NAD}^{+}$, nitro blue tetrazolium chloride (NBT) or phenazine methosulfate (PMS), and negative controls without $\mathrm{H}_{2}$ or without cell extracts showed no activity (Supplementary Table 2). In accordance with the quantitative PCR results, there was not much difference in the activity levels between pyruvate/PCE- and $\mathrm{H}_{2} / \mathrm{PCE}$ grown cells, with a specific $\mathrm{H}_{2}$-oxidizing activity of $60 \mathrm{nkat} / \mathrm{mg}$ protein with $\mathrm{BV}$ as electron acceptor for pyruvate/PCE cells, $50 \mathrm{nkat} / \mathrm{mg}$ for pyruvate/fumarate cells and $70 \mathrm{nkat} / \mathrm{mg}$ for $\mathrm{H}_{2} / \mathrm{PCE}$ cells (Figure 5A). Crude extracts obtained from cells grown with pyruvate as electron donor and $5 \% \mathrm{O}_{2}$ as electron acceptor showed $\mathrm{H}_{2}$-dependent enzyme activity with BV (25 $\pm 2.3 \mathrm{nkat} / \mathrm{mg})$. After subcellular fractionation, the highest specific activity (about $60 \mathrm{nkat} / \mathrm{mg}$ ) was found in the MF while only around one tenth (7 and 5 nkat/mg for extracts obtained from pyruvate- and $\mathrm{H}_{2}$-grown cells, respectively) was measured for the SF. The activities of crude extract, MF and solubilized MEs were about 50 to $70 \mathrm{nkat} / \mathrm{mg}$ (Figure 5B).

The different subcellular fractions were subjected to native PAGE followed by activity staining. This method allows to estimate the size and activity of catalytically active enzyme complexes and is often routinely used for the characterization of hydrogenases (Ballantine and Boxer, 1985; Pinske et al., 2012). For this purpose, S. multivorans cells were grown with either pyruvate or $\mathrm{H}_{2}$ as electron donor and PCE as electron acceptor. Both, cell extracts and subcellular fractions (SF and ME solubilized with digitonin), were subjected to activity staining with BV as primary and TTC (triphenyl tetrazolium chloride) as secondary electron acceptor. After incubation of the gel with $\mathrm{H}_{2}$ for $15-30 \mathrm{~min}$ at $28^{\circ} \mathrm{C}$, a distinct band showing the typical reddish color of reduced TTC appeared at a size of about $270 \mathrm{kDa}$. This band was missing or only weakly visible in the SF (Figure 6). A prolonged incubation time up to $12 \mathrm{~h}$ did not lead to an additional band in the activity staining with membrane or SFs, suggesting the involvement of only one hydrogenase in $\mathrm{H}_{2}$ oxidation, albeit a hydrogenase not performing $\mathrm{H}_{2}$ oxidation under the given conditions might have been overlooked in this assay. The size of $270 \mathrm{kDa}$ correlates to a dimeric form of the heterotrimeric $S$. multivorans $\mathrm{MBH}$, which is predicted to be around $244 \mathrm{kDa}$ (predicted sizes for the maturated $\mathrm{MBH}$ - large subunit HydB: $62 \mathrm{kDa}$, small subunit HydA: $34 \mathrm{kDa}$, and the membrane-integral cytochrome $b$, HydC: $26 \mathrm{kDa}$ ). This value, however, does not take into account the unknown contribution of the digitonin micelle size.

The presumable physiological electron acceptor for the $\mathrm{MBH}$ is menaquinone, as was shown for the $\mathrm{MBH}$ from $W$. succinogenes (Dross et al., 1992). To test the $\mathrm{H}_{2}$-dependent reactivity of the $\mathrm{MBH}$ of $\mathrm{S}$. multivorans with quinones, $\mathrm{H}_{2}$ oxidation activity was measured spectrophotometrically with two different quinone analogs. Similar to the $\mathrm{MBH}$ of $W$. succinogenes, crude and MEs of S. multivorans showed activity with 2,3-dimethyl-1,4naphtoquinone (DMN) (Table 1). Extracts from cells grown with $\mathrm{H}_{2}$ showed approximately $10 \%$ higher activities than those from cells grown with pyruvate (Table 1). The hydrophilic quinone analog, 1,4-naphthoquinone, was neither reduced by the $\mathrm{MBH}$ of S. multivorans nor by that of W. succinogenes (Dross et al., 1992).

To investigate the involvement of a cytochrome $b$, spectroscopic changes in UV/VIS absorption of MFs were recorded before and after the addition of $\mathrm{H}_{2}$. The MF showed an absorption maximum at $414 \mathrm{~nm}$ in the absence of $\mathrm{H}_{2}$. After flushing the sample with $\mathrm{H}_{2}$, the Soret band at $414 \mathrm{~nm}$ shifted to $427 \mathrm{~nm}$ and two peaks at 530 and $561 \mathrm{~nm}$ appeared (Figure 7A).
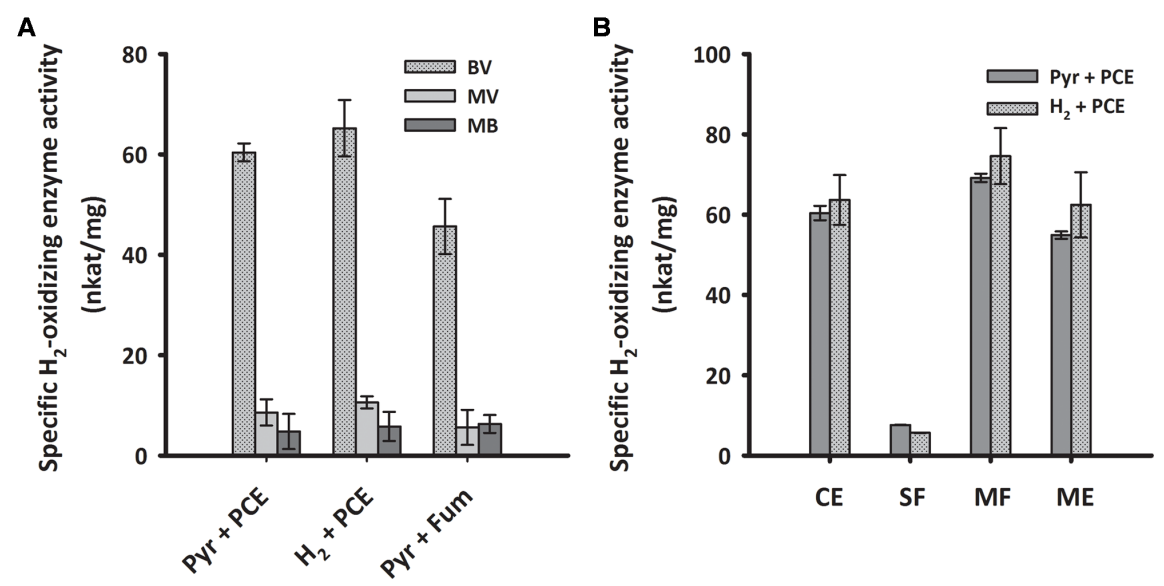

FIGURE 5 | $\mathbf{H}_{\mathbf{2}}$-oxidizing activities of crude extracts with different redox dyes (A) and enzyme activity of subcellular fractions of $S$. multivorans measured with benzyl viologen (B). (A) Specific $\mathrm{H}_{2}$-oxidizing enzyme activity (nkat/mg) of crude extracts from cells grown under different cultivation conditions. (B) Specific $\mathrm{H}_{2}$-oxidizing enzyme activity (nkat/mg) of different cell fractions from pyruvate/PCE and $\mathrm{H}_{2} / \mathrm{PCE}$-grown cells. Data are calculated from three independent biological and technical replicates. Cells were fractionated according to the "Experimental Procedures" section and solubilization was done with 0.1\% Triton X-100. For concentrations of redox dyes, see section "Experimental Procedures". BV, benzyl viologen; MV, methyl viologen; MB, methylene blue. Pyr, pyruvate; Fum, fumarate; $\mathrm{CE}$, crude extract; SF, soluble fraction; MF, membrane fraction; ME, membrane extract. 


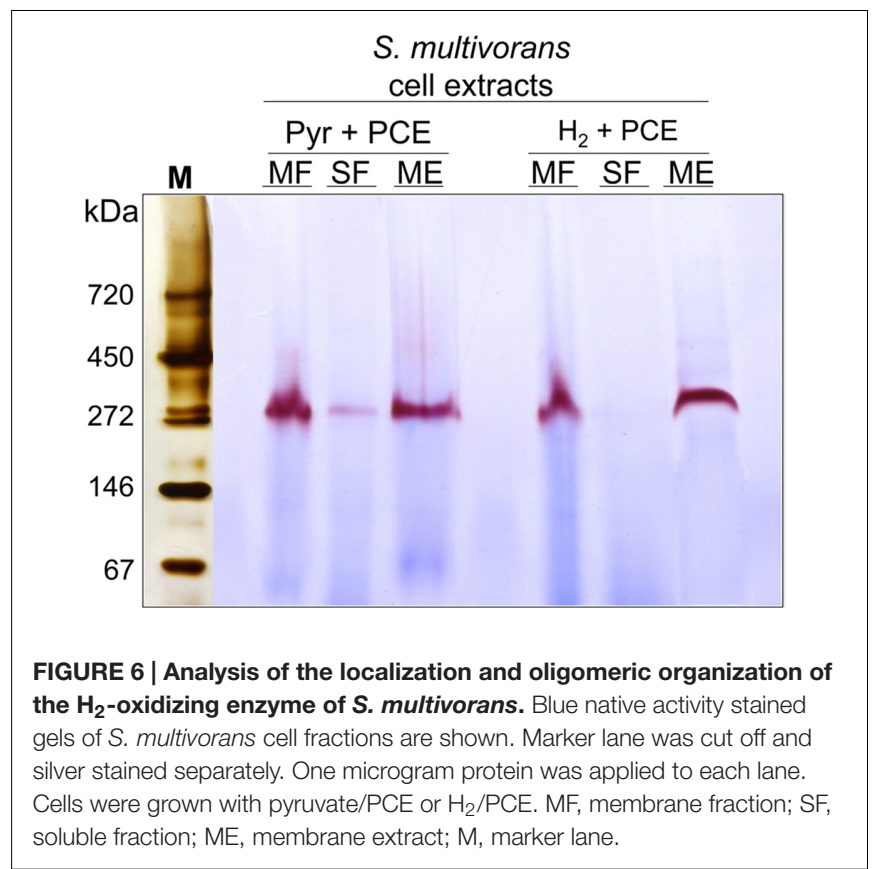

When calculating the difference spectra of $\mathrm{H}_{2}$-reduced minus oxidized state, the spectrum showed $\alpha-, \beta$-, and $\gamma$-absorption peaks at 561, 530, and $427 \mathrm{~nm}$, respectively (Figure 7B). These spectral properties correspond to absorption spectra of $b$-type cytochromes (Yoon et al., 2008; Eguchi et al., 2012).

\section{Enrichment of the Membrane-Bound Hydrogenase}

Attempts to express the MBH of S. multivorans heterologously did not lead to the formation of an active enzyme, therefore, an enrichment from MEs was carried out (Figure 8). After solubilization of the MF with digitonin, $18 \%$ of hydrogenase enzyme activity from the MF could be recovered. An enrichment
TABLE 1 | $\mathrm{H}_{2}$-oxidizing activities of different cell fractions with DMN as electron acceptor.

\begin{tabular}{lcc}
\hline Growth substrates & Cell fraction & $\begin{array}{c}\text { Specific hydrogenase } \\
\text { activity (nkat/mg) } \\
\mathbf{H}_{\mathbf{2}} \text {-> } \mathbf{\text { DMN }}\end{array}$ \\
\hline Pyruvate + PCE & ME & $41.9 \pm 4.67$ \\
$\mathrm{H}_{2}+\mathrm{PCE}$ & $\mathrm{MF}$ & $26.9 \pm 3.14$ \\
& $\mathrm{ME}$ & $54.4 \pm 5.57$ \\
& $\mathrm{MF}$ & $29.9 \pm 6.38$
\end{tabular}

$D M N$, 2,3-dimethyl-1,4-naphthoquinone; MF, membrane fraction; ME, membrane extract (solubilized membranes).

of 221-fold was obtained using anion exchange chromatography with a Q-Sepharose column (Table 2). After elution, the fractions with the highest activities (fractions 19-23) were applied to SDS-PAGE, native PAGE and BN activity staining (Supplementary Figure 2). In the latter, all fractions showed the remarkable red band at $270 \mathrm{kDa}$, which was most intense in fractions 20 and 21. Similar to the cell extracts, no second band was visible after prolonged incubation (up to $12 \mathrm{~h}$ ) in the reaction mixture. Silver stained native PAGE showed the same $270 \mathrm{kDa}$ band in all applied fractions with the most intense band in fraction 20 (Figure 8A). Other distinct bands in fraction 20 appeared around 50 and $130 \mathrm{kDa}$. After SDSPAGE, all tested fractions showed a band at about $65 \mathrm{kDa}$, which corresponds to the size of $\mathrm{HydB}(62 \mathrm{kDa})$. This band was strongest in fractions 20 and 21. Additionally, a band at nearly $35 \mathrm{kDa}$ was showing up in fractions 20 to 23 , correlating to the theoretical size of the mature small subunit of the $\mathrm{MBH}(34 \mathrm{kDa})$. Several bands between 25 and $30 \mathrm{kDa}$ were visible in all fractions, but none of them could be attributed clearly to HydC $(26 \mathrm{kDa})$. One predominant band at $25 \mathrm{kDa}$ observed in fractions 20 and 21 might represent a cytochrome $b$, especially since both fractions showed activity with DMN as electron acceptor (Supplementary Figure 2). Fraction 20 appeared to exhibit less additional bands than
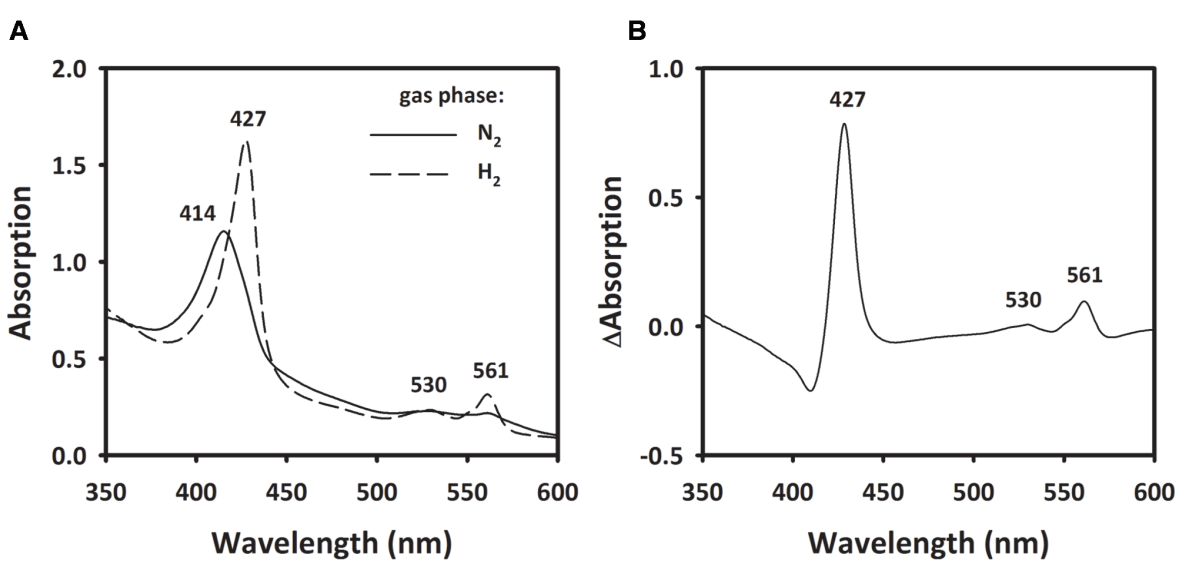

FIGURE 7 | Absorption spectra of membrane extract of $\mathbf{S}$. multivorans. (A) The solid line represents the membrane fraction under $\mathrm{N}_{2}$ as gas phase. Incubation of the sample for 10 min under $\mathrm{H}_{2}$ leads to the spectrum represented by the dashed line (B) Difference spectra of the $\mathrm{H}_{2}$-reduced minus $\mathrm{N}_{2}$-incubated state. Numbers indicate wavelengths of characteristic absorption peaks of $b$-type cytochromes. Cells were grown with pyruvate/PCE. 


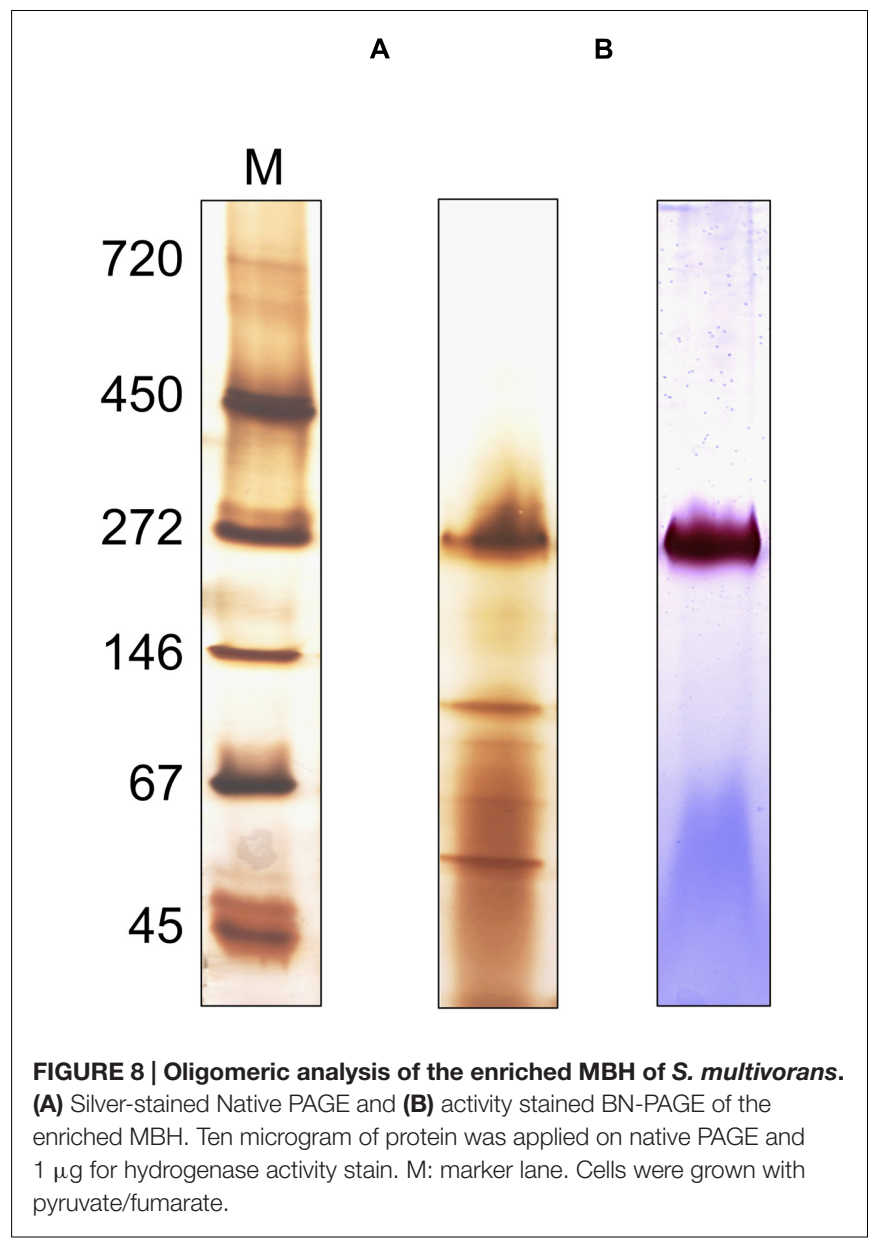

fraction 21 after SDS-PAGE (Supplementary Figure 2), therefore, we chose this fraction for further purification. Hydrophobic interaction chromatography or gel filtration did not lead to further enrichment of active trimeric $\mathrm{MBH}$, so that further characterization was performed with fraction 20 . The presence of the membrane-integral cytochrome $b(\mathrm{HydC})$ in this fraction was shown using UV/Vis spectroscopy. The same characteristic absorption spectra and difference spectrum were recorded as those obtained for the MF (Supplementary Figure 3). Compared to the membranes, the enriched $\mathrm{MBH}$ showed a higher absorption in the difference spectrum, suggesting a higher cytochrome $b$ concentration. The optimal condition for $\mathrm{H}_{2}$ oxidation by fraction 20 was at $\mathrm{pH} 8.0$ and $40^{\circ} \mathrm{C}$ when $\mathrm{BV}$ was used as electron acceptor in the photometric assay.

\section{DISCUSSION}

To identify hydrogenases involved in the hydrogen-oxidation during PCE respiration in S. multivorans, we performed transcription analysis and biochemical investigations with cells grown in the presence of different electron donor/acceptor combinations. Of the previously identified four $\mathrm{NiFe}$ hydrogenases encoded in the genome of S. multivorans, a membrane-bound hydrogenase similar to the hydrogenoxidizing MBH from $W$. succinogenes was suggested to play a role in hydrogen oxidation during PCE respiration. However, the only evidence for this assumption was based on amino acid sequence similarities to other hydrogen-oxidizing enzymes and cell extracts grown with $\mathrm{H}_{2}$ and fumarate (Miller et al., 1996; Goris et al., 2014), which did not allow for an unambiguous conclusion of its role in PCE respiration. Since up to now no detailed information on the composition of organohalide respiratory chains is available, it is feasible that one of the other three hydrogenases might be involved. In the transcript level analysis presented here, only two of the four hydrogenase large subunit genes were found to be transcribed to a considerable amount. The first is $h y d B$, encoding the large subunit of the MBH similar to that of $W$. succinogenes, while the second, $h y f G$, belongs to a group 4 hydrogenase (Vignais and Billoud, 2007) similar to hydrogenases 3 and 4 of E. coli (Hyc and Hyf). The $h y d B$ transcript level was found not to be significantly altered during any of the tested growth conditions. The presence of the $\mathrm{MBH}$ and Hyf with pyruvate or formate as electron donor was already seen in a previous proteomic study (Goris et al., 2015) (Supplementary Data Sheet 3). This points toward a constitutive expression of the $\mathrm{MBH}$ in S. multivorans. As this was tested in cells long-term cultivated without $\mathrm{H}_{2}$, a regulatory effect as reported earlier for PCE respiration (John et al., 2009) can be also excluded.

Post-transcriptional regulation and maturation could also have an influence on the hydrogen-oxidizing activity and the responsible hydrogenase. The biochemical analyses with extracts obtained from cells grown under different conditions revealed comparable $\mathrm{H}_{2}$-oxidizing activities regardless of the electron donor or acceptor used. Also, $\mathrm{H}_{2}$ had no apparent influence on the maturation of the $\mathrm{MBH}$, since the $\mathrm{H}_{2}$-oxidizing activity in the ME did not change when cultures were grown with $\mathrm{H}_{2}$. Furthermore, we conclude that only one hydrogenase plays a role in hydrogen oxidation under all growth conditions tested, since only one band was detected in $\mathrm{BN}$ activity staining regardless of the growth condition. However, the blue native activity staining was performed only with the primary electron acceptor BV. Therefore, the presence of another hydrogen-oxidizing enzyme

TABLE 2 | Enrichment of membrane-bound hydrogenase of S. multivorans.

\begin{tabular}{|c|c|c|c|c|c|}
\hline Purification step & Activity (nkat/ml) & Protein $(\mathrm{mg} / \mathrm{ml})$ & Specific activity (nkat/mg) & Yield (\%) & Purification (fold) \\
\hline Membrane fraction & 92 & 20 & 4.6 & 100 & 1 \\
\hline Digitonin solubilization & 403.1 & 3.6 & 112 & 18 & 24.3 \\
\hline Q-Sepharose HP & 1326 & 1.3 & 1020 & 6.5 & 221 \\
\hline
\end{tabular}

Enzyme activity was measured with benzyl viologen. Cells were grown with pyruvate/fumarate. 
requiring a different electron acceptor cannot be completely ruled out. Activity-stained BN PAGE of a hydrogen-oxidizing enzyme enriched from S. multivorans showed a band corresponding to the same size. SDS PAGE analysis of the subunit composition revealed subunits with molecular masses corresponding to the three subunits HydABC of the MBH. Spectroscopic analysis of the enriched enzyme revealed characteristic spectra of $b$-type cytochromes, indicating the presence of a cytochrome $b$ in the enrichment. These results are in accordance with spectra obtained from membranes and from the purified MBH of $W$. succinogenes. In addition, the $\mathrm{H}_{2}$-dependent reduction of the quinone analog DMN indicates that electrons derived from $\mathrm{H}_{2}$ oxidation are transferred via the membrane-integral cytochrome $b$ to the menaquinone pool (Figure 9A). Previous studies suggested the involvement of menaquinone and a quinol dehydrogenase in the PCE respiratory chain (Goris et al., 2014, 2015), which supports the assumption that the MBHmediated hydrogen oxidation is coupled to PCE reduction via menaquinone.

The apparent molecular mass of the native enzyme points to a heterotrimeric $\mathrm{MBH}$ dimer. This is opposed to a putative trimeric composition of the heterotrimeric complex of Cupriavidus necator MBH (Frielingsdorf et al., 2011). Instead, the S. multivorans complex resembles the E. coli hydrogenase 1 crystallized as a heterotrimer (Volbeda et al., 2013), albeit the latter was reported to contain only one cytochrome for a hydrogenase dimer. A dimeric structure is not only found for E. coli hydrogenase 1, but also found in several other hydrogenase crystal structures, although these were solved without a membrane-integral subunit (Wulff et al., 2016).

The broad array of growth conditions used for real-time PCR experiments in this study revealed that under none of the conditions tested neither hupL nor echE were induced. In contrast, $h y d B$ was expressed under all growth conditions, even with $\mathrm{O}_{2}$ as electron acceptor. The latter observation was surprising, since Epsilonproteobacteria including S. multivorans do not harbor oxygen-tolerant NiFe hydrogenases and most NiFe hydrogenases suffer from inactivation when exposed to $\mathrm{O}_{2}$. Therefore, many facultative anaerobic bacteria employ mechanisms to down-regulate the expression of hydrogenase genes in the presence of $\mathrm{O}_{2}$. For example, hydrogenase gene transcription is under control of regulators ArcAB and Fnr in other facultative anaerobic proteobacteria including E. coli (Richard et al., 1999; Kovács et al., 2005). None of these regulators is found in Epsilonproteobacteria, which might explain the lack of $\mathrm{O}_{2}$-induced down-regulation of hydrogenase gene expression. Many free-living Epsilonproteobacteria are facultative microaerophilic and often found in the oxicanoxic interface, where the $\mathrm{O}_{2}$ concentration varies (Vetriani et al., 2003; Grote et al., 2012). Therefore, a constitutive expression of the hydrogen-uptake system and the lack of an $\mathrm{O}_{2}$-sensitive regulation system may be beneficial to these organisms. Although all attempts to grow $S$. multivorans with $\mathrm{H}_{2}$ and $\mathrm{O}_{2}$ as energy substrates failed so far, it is feasible that the organism might use $\mathrm{H}_{2}$ as additional electron donor under very low $\mathrm{O}_{2}$ partial pressure as described elsewhere for other Epsilonproteobacteria (e.g., Campylobacter jejuni and
Helicobacter pylori) (Laanbroek et al., 1977, 1978; Carlone and Lascelles, 1982; Maier et al., 2003). Since crude extracts from cells grown with $\mathrm{O}_{2}$ still showed around half of the activity as anaerobically grown cells, this seems feasible for S. multivorans.

The presence of $\mathrm{H}_{2}$ in the gas phase did not raise the transcript level of the MBH significantly. On the molecular level, this might be attributed to a missing $\mathrm{H}_{2}$ sensor such as that found in some "Knallgas" bacteria (Kleihues et al., 2000; Friedrich et al., 2005). The absence of regulatory proteins with the exception of the nickel-dependent NikR (Goris et al., 2014) is in accordance with a constitutive expression of the MBH in S. multivorans. The constitutive expression of the $\mathrm{MBH}$ might also be an advantage in anoxic environments where nutrient composition and $\mathrm{H}_{2}$ levels are often changing.

The role of the Hyf hydrogenase in S. multivorans remains enigmatic. The key enzyme in mixed acid fermentation in E. coli is the pyruvate formate lyase (PFL), generating formate, which is the substrate for the FHL complex. An ortholog of the PFL is not encoded in the genome of S. multivorans. While the amino acid sequences of S. multivorans Hyf subunits are similar (33 to 50\% amino acid sequence identity) to those of hydrogenase 4 of $E$. coli, the S. multivorans hyf gene cluster does not contain any genes encoding formate-metabolism related proteins as found in the $h y f$ cluster of $E$. coli (e.g., the formate channel $f o c B$ or a formatesensitive transcriptional regulator). A gene encoding a putative cytoplasmic formate dehydrogenase is found in the genome of S. multivorans, but the according protein sequence shows only $30 \%$ amino acid sequence identity to FdhF of the FHL complex of E. coli. Additionally, an ortholog of the S. multivorans Fdh is found in many epsilonproteobacterial genomes not encoding the Hyf hydrogenase. All this renders participation of Hyf in an FHL complex in S. multivorans an unlikely scenario. Instead, we assume that Hyf could serve to dispose of excess reducing equivalents, accepting electrons, e.g., from ferredoxin reduced by a pyruvate:ferredoxin oxidoreductase (PFOR), similar to the group 4 hydrogenase of Pyrococcus furiosus (McTernan et al., 2015). The ferredoxin and the PFOR were found to be present in the proteome in S. multivorans previously (Goris et al., 2015). We assume that $S$. multivorans produces $\mathrm{H}_{2}$ especially under fermentative conditions (Figure 9B) or when the concentration of the electron acceptor may be limiting. This is probably the case for PCE, which, even in polluted environments, could be present at low concentrations due to its low solubility. In contrast, nitrate may be available at higher concentrations, which might explain the down-regulation exclusively with $\mathrm{H}_{2}$ /nitrate as substrates. The role and function of this hydrogenase is subject to further studies currently conducted in our laboratory.

The role of the cytoplasmic uptake hydrogenase HupSL remains unclear in S. multivorans. A TetR-like transcriptional repressor which is encoded directly upstream of the hupSL cluster (Goris et al., 2014) might repress the transcription of the enzyme under the tested growth conditions. The function of HupSL in recycling of $\mathrm{H}_{2}$ as a byproduct of $\mathrm{N}_{2}$ fixation can be excluded, since growth with $\mathrm{N}_{2}$ as sole $\mathrm{N}$-source did not lead to an elevated transcript level, which would have been expected in that case. A role in reducing a cytoplasmic low-potential 

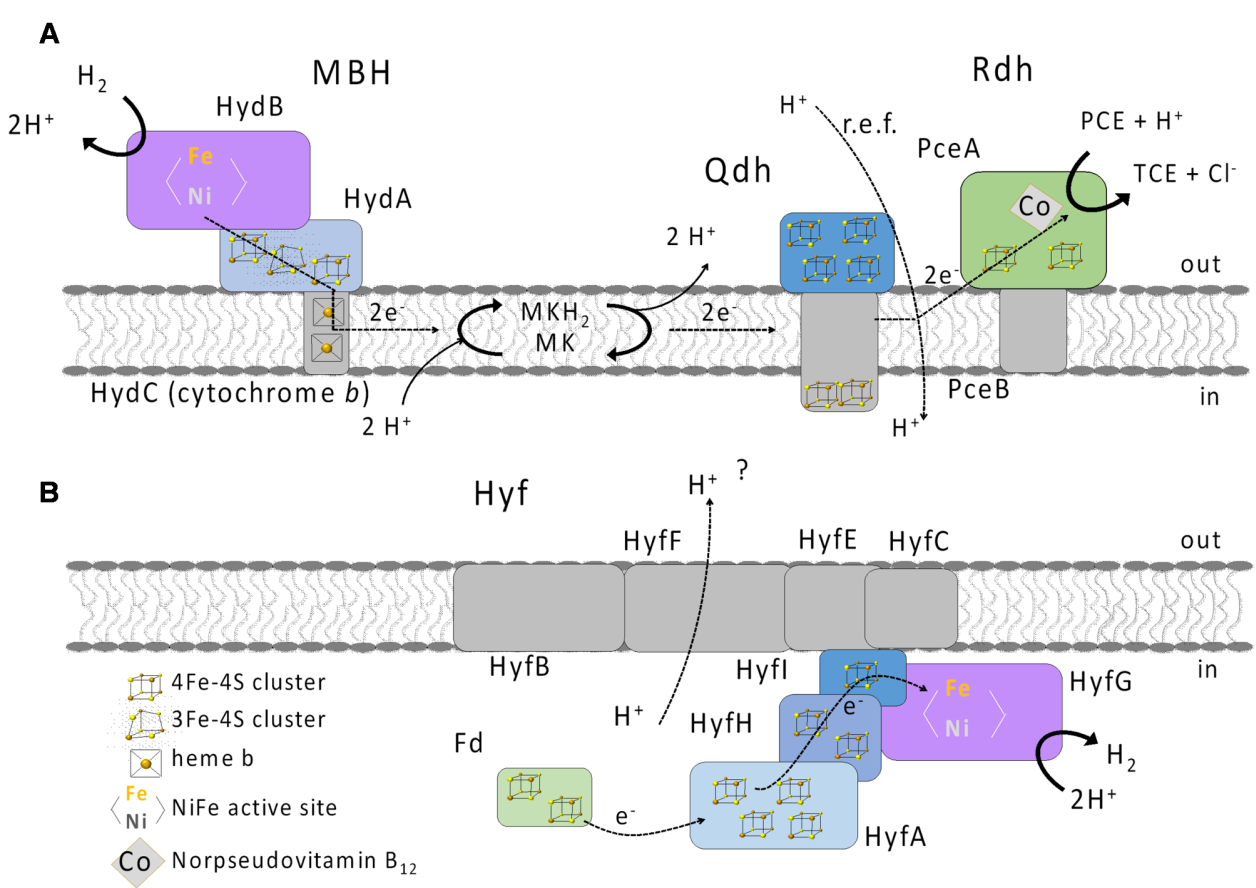

FIGURE 9 | Putative physiological roles of the $\mathbf{M B H}(\mathbf{A})$ and Hyf hydrogenase (B) in S. multivorans. Qdh, quinol dehydrogenase; PceAB, PCE reductive dehalogenase; MK, menaquinone; MKH2, reduced MK; Fd, ferredoxin; PCE, tetrachloroethene; TCE, trichloroethene; i, inside (cytoplasm); o, outside (periplasm).

electron donor such as reduced ferredoxin providing electrons for the reductive TCA cycle seems feasible, as was suggested for a similar hydrogenase in A. aeolicus (Guiral et al., 2005). The proteins for the rTCA cycle are encoded in the genome of S. multivorans (Goris et al., 2014), but autotrophic growth was never observed. Like for the hupL gene, also echE transcripts were only found in negligible amounts in this study. All Ech subunits bear high similarity to the $\mathrm{CO}$-induced hydrogenase of $C$. hydrogenoformans, in which the hydrogenase genes are located adjacent to a CO dehydrogenase gene (Soboh et al., 2002). In the genome of Sulfurospirillum sp. SCADC, this structure is still conserved (Tan and Foght, 2014; Goris and Diekert, 2016) and S. carboxydovorans is reported to use CO as electron donor (Jensen and Finster, 2005). Hence, a loss of the CO dehydrogenase gene and non-functionality of the CO-induced like hydrogenase in S. multivorans is possible. However, it is also feasible that growth conditions, which induce transcription of the hup and ech genes, were not tested in this study. For example, $\mathrm{pH}$ variation or different levels of $\mathrm{H}_{2}$ concentrations, which could have an effect on hydrogenase expression, was not included here.

\section{CONCLUSION}

In this study we showed that $S$. multivorans involves a membranebound NiFe hydrogenase similar to the $\mathrm{MBH}$ of $W$. succinogenes for $\mathrm{H}_{2}$ oxidation in the PCE-respiratory chain. The MBH, which was enriched with a redox-active, membrane-integral cytochrome $b$, reacts most likely with the quinone pool and forms a native complex of around $270 \mathrm{kDa}$. The transcript studies presented here show that the $\mathrm{MBH}$ is not subject to a distinct $\mathrm{H}_{2}$ - or $\mathrm{O}_{2}$-dependent regulation as reported for other organisms. Besides the $\mathrm{MBH}$, only one more hydrogenase gene transcript (Hyf type) was found under the growth conditions applied in this study. This cytoplasmic, membrane-bound hydrogenase complex with similarities to Hyf from E. coli is most likely playing a role in proton reduction under electron acceptor-limiting conditions.

Taken together, this study allows a deeper insight into the $\mathrm{H}_{2}$ metabolism of a model organohalide-respiring bacterium and a free-living Epsilonproteobacterium.

\section{AUTHOR CONTRIBUTIONS}

TG and GD initiated and supervised the study, SK and TG designed experiments, analyzed data and drafted the manuscript. SK performed the biochemical and real-time PCR experiments, MW performed initial real-time PCR experiments, including primer design and testing of optimal conditions, XW performed initial biochemical experiments. All authors curated, read, and approved the final manuscript.

\section{FUNDING}

This work was supported by the German Research Foundation (DFG) as part of the graduate school of excellence JSMC (Jena School for Microbial Communication) grant number GSC 214 and by the DFG-research unit FOR 1530. 


\section{ACKNOWLEDGMENTS}

The authors would like to thank Akos Kovacs (Friedrich Schiller University Jena) for helpful comments on the real-time PCR data and presentation. We are grateful to all involved reviewers for their useful remarks.

\section{REFERENCES}

Ballantine, S. P., and Boxer, D. H. (1985). Nickel-containing hydrogenase isoenzymes from anaerobically grown Escherichia coli K-12. J. Bacteriol. 163, 454-459.

Bothe, H., Schmitz, O., Yates, M. G., and Newton, W. E. (2010). Nitrogen fixation and hydrogen metabolism in cyanobacteria. Microbiol. Mol. Biol. Rev. 74 529-551. doi: 10.1128/MMBR.00033-10

Bradford, M. M. (1976). A rapid and sensitive method for the quantitation of microgram quantities of protein utilizing the principle of protein-dye binding. Anal. Biochem. 72, 248-254. doi: 10.1016/0003-2697(76)90527-3

Carlone, G. M., and Lascelles, J. (1982). Aerobic and anaerobic respiratory systems in Campylobacter fetus subsp. jejuni grown in atmospheres containing hydrogen. J. Bacteriol. 152, 306-314.

Dross, F., Geisler, V., Lenger, R., Theis, F., Krafft, T., Fahrenholz, F., et al. (1992). The quinone-reactive $\mathrm{Ni} / \mathrm{Fe}-$ hydrogenase of Wolinella succinogenes. Eur. J. Biochem. 206, 93-102. doi: 10.1111/j.1432-1033.1992.tb16905.x

Eguchi, S., Yoon, K. S., and Ogo, S. (2012). O2-stable membrane-bound [NiFe]hydrogenase from a newly isolated Citrobacter sp. S-77. J. Biosci. Bioeng. 114, 479-484. doi: 10.1016/j.jbiosc.2012.05.018

Friedrich, B., Buhrke, T., Burgdorf, T., and Lenz, O. (2005). A hydrogen-sensing multiprotein complex controls aerobic hydrogen metabolism in Ralstonia eutropha. Biochem. Soc. Trans. 33, 97-101. doi: 10.1042/BST0330097

Frielingsdorf, S., Schubert, T., Pohlmann, A., Lenz, O., and Friedrich, B. (2011). A trimeric supercomplex of the oxygen-tolerant membrane-bound [NiFe]hydrogenase from Ralstonia eutropha H16. Biochemistry 50, 10836-10843. doi: 10.1021/bi201594m

Goris, T., and Diekert, G. (2016). "The genus Sulfurospirillum," in OrganohalideRespiring Bacteria, eds L. Adrian and F. Löffler (Berlin: Springer).

Goris, T., Schiffmann, C. L., Gadkari, J., Schubert, T., Seifert, J., Jehmlich, N., et al. (2015). Proteomics of the organohalide-respiring Epsilonproteobacterium Sulfurospirillum multivorans adapted to tetrachloroethene and other energy substrates. Sci. Rep. 5:13794. doi: 10.1038/srep13794

Goris, T., Schubert, T., Gadkari, J., Wubet, T., Tarkka, M., Buscot, F., et al. (2014). Insights into organohalide respiration and the versatile catabolism of Sulfurospirillum multivorans gained from comparative genomics and physiological studies. Environ. Microbiol. 16, 3562-3580. doi: 10.1111/14622920.12589

Greening, C., Biswas, A., Carere, C. R., Jackson, C. J., Taylor, M. C., Stott, M. B., et al. (2016). Genomic and metagenomic surveys of hydrogenase distribution indicate $\mathrm{H} 2$ is a widely utilised energy source for microbial growth and survival. ISME J. 10, 761-777. doi: 10.1038/ismej.2015.153

Greening, C., and Cook, G. M. (2014). Integration of hydrogenase expression and hydrogen sensing in bacterial cell physiology. Curr. Opin. Microbiol. 18, 30-38. doi: 10.1016/j.mib.2014.02.001

Gross, R., Pisa, R., Sänger, M., Lancaster, C. R., and Simon, J. (2004). Characterization of the menaquinone reduction site in the diheme cytochrome b membrane anchor of Wolinella succinogenes NiFe-hydrogenase. J. Biol. Chem. 279, 274-281. doi: 10.1074/jbc.M310610200

Grote, J., Schott, T., Bruckner, C. G., Glöckner, F. O., Jost, G., Teeling, H., et al. (2012). Genome and physiology of a model Epsilonproteobacterium responsible for sulfide detoxification in marine oxygen depletion zones. Proc. Natl. Acad. Sci. U.S.A. 109, 506-510. doi: 10.1073/pnas.1111262109

Guiral, M., Aubert, C., and Giudici-Orticoni, M. T. (2005). Hydrogen metabolism in the hyperthermophilic bacterium Aquifex aeolicus. Biochem. Soc. Trans. 33, 22-24. doi: 10.1042/BST0330022

Hedderich, R., and Forzi, L. (2005). Energy-converting [NiFe] hydrogenases: more than just H2 activation. J. Mol. Microbiol. Biotechnol. 10, 92-104. doi: 10.1159/ 000091557

\section{SUPPLEMENTARY MATERIAL}

The Supplementary Material for this article can be found online at: http://journal.frontiersin.org/article/10.3389/fmicb. 2017.00444/full\#supplementary-material

Holliger, C., Hahn, D., Harmsen, H., Ludwig, W., Schumacher, W., Tindall, B., et al. (1998). Dehalobacter restrictus gen. nov. and sp. nov., a strictly anaerobic bacterium that reductively dechlorinates tetra- and trichloroethene in an anaerobic respiration. Arch. Microbiol. 169, 313-321. doi: 10.1007/ s002030050577

Jensen, A., and Finster, K. (2005). Isolation and characterization of Sulfurospirillum carboxydovorans sp nov., a new microaerophilic carbon monoxide oxidizing epsilon Proteobacterium. Antonie Van Leeuwenhoek 87, 339-353. doi: 10.1007/ s10482-004-6839-y

John, M., Rubick, R., Schmitz, R. P., Rakoczy, J., Schubert, T., and Diekert, G. (2009). Retentive memory of bacteria: long-term regulation of dehalorespiration in Sulfurospirillum multivorans. J. Bacteriol. 191, 1650-1655. doi: 10.1128/JB.00597-08

Ju, X., Zhao, L., and Sun, B. (2007). Nitrogen fixation by reductively dechlorinating bacteria. Environ. Microbiol. 9, 1078-1083. doi: 10.1111/j.1462-2920.2006. 01199.x

Kleihues, L., Lenz, O., Bernhard, M., Buhrke, T., and Friedrich, B. (2000). The H2 sensor of Ralstonia eutropha is a member of the subclass of regulatory [NiFe] hydrogenases. J. Bacteriol. 182, 2716-2724. doi: 10.1128/JB.182.10.2716-2724. 2000

Kovács, A. T., Rákhely, G., Balogh, J., Maróti, G., Fülöp, A., and Kovács, K. L. (2005). Anaerobic regulation of hydrogenase transcription in different bacteria. Biochem. Soc. Trans. 33, 36-38. doi: 10.1042/BST0330036

Kruse, T., Maillard, J., Goodwin, L., Woyke, T., Teshima, H., Bruce, D., et al. (2013). Complete genome sequence of Dehalobacter restrictus PER-K23(T.) Stand. Genomic Sci. 8, 375-388. doi: 10.4056/sigs.3787426

Kruse, T., van de Pas, B. A., Atteia, A., Krab, K., Hagen, W. R., Goodwin, L., et al. (2015). Genomic, proteomic, and biochemical analysis of the organohalide respiratory pathway in Desulfitobacterium dehalogenans. J. Bacteriol. 197, 893-904. doi: 10.1128/JB.02370- 14

Kube, M., Beck, A., Zinder, S. H., Kuhl, H., Reinhardt, R., and Adrian, L. (2005). Genome sequence of the chlorinated compound-respiring bacterium Dehalococcoides species strain CBDB1. Nat. Biotechnol. 23, 1269-1273. doi: $10.1038 / \mathrm{nbt} 1131$

Laanbroek, H., Kingma, W., and Veldkamp, H. (1977). Isolation of an aspartatefermenting, free-living Campylobacter species. FEMS Microbiol. Lett. 1, 99-102. doi: 10.1111/j.1574-6968.1977.tb00590.x

Laanbroek, H. J., Stal, L. H., and Veldkamp, H. (1978). Utilization of hydrogen and formate by Campylobacter spec. under aerobic and anaerobic conditions. Arch. Microbiol. 119, 99-102. doi: 10.1007/BF00407935

Löffler, F. E., Yan, J., Ritalahti, K. M., Adrian, L., Edwards, E. A., Konstantinidis, K. T., et al. (2013). Dehalococcoides mccartyi gen. nov., sp. nov., obligately organohalide-respiring anaerobic bacteria relevant to halogen cycling and bioremediation, belong to a novel bacterial class, Dehalococcoidia classis nov., order Dehalococcoidales ord. nov. and family Dehalococcoidaceae fam. nov., within the phylum Chloroflexi. Int. J. Syst. Evol. Microbiol. 63, 625-635. doi: 10.1099/ijs.0.034926-0

Luijten, M. L., de Weert, J., Smidt, H., Boschker, H. T., de Vos, W. M., Schraa, G., et al. (2003). Description of Sulfurospirillum halorespirans sp. nov., an anaerobic, tetrachloroethene-respiring bacterium, and transfer of Dehalospirillum multivorans to the genus Sulfurospirillum as Sulfurospirillum multivorans comb. nov. Int. J. Syst. Evol. Microbiol. 53, 787-793. doi: 10.1099/ ijs.0.02417-0

Maier, R. J., Olson, J., and Olczak, A. (2003). Hydrogen-oxidizing capabilities of Helicobacter hepaticus and in vivo availability of the substrate. J. Bacteriol. 185, 2680-2682. doi: 10.1128/JB.185.8.2680-2682.2003

Mansfeldt, C. B., Rowe, A. R., Heavner, G. L., Zinder, S. H., and Richardson, R. E. (2014). Meta-analyses of Dehalococcoides mccartyi strain 195 transcriptomic profiles identify a respiration rate-related gene expression 
transition point and interoperon recruitment of a key oxidoreductase subunit. Appl. Environ. Microbiol. 80, 6062-6072. doi: 10.1128/AEM. 02130-14

McTernan, P. M., Chandrayan, S. K., Wu, C. H., Vaccaro, B. J., Lancaster, W. A., and Adams, M. W. (2015). Engineering the respiratory membranebound hydrogenase of the hyperthermophilic archaeon Pyrococcus furiosus and characterization of the catalytically active cytoplasmic subcomplex. Protein Eng. Des. Sel. 28, 1-8. doi: 10.1093/protein/gzu051

Miller, E., Wohlfarth, G., and Diekert, G. (1996). Studies on tetrachloroethene respiration in Dehalospirillum multivorans. Arch. Microbiol. 166, 379-387. doi: 10.1007/BF01682983

Nonaka, H., Keresztes, G., Shinoda, Y., Ikenaga, Y., Abe, M., Naito, K., et al. (2006). Complete genome sequence of the dehalorespiring bacterium Desulfitobacterium hafniense Y51 and comparison with Dehalococcoides ethenogenes 195. J. Bacteriol. 188, 2262-2274. doi: 10.1128/JB.188.6.2262-2274. 2006

Pinske, C., Jaroschinsky, M., Sargent, F., and Sawers, G. (2012). Zymographic differentiation of [NiFe]-hydrogenases 1, 2 and 3 of Escherichia coli K-12. BMC Microbiol. 12:134. doi: 10.1186/1471-2180-12-134

Richard, D. J., Sawers, G., Sargent, F., McWalter, L., and Boxer, D. H. (1999). Transcriptional regulation in response to oxygen and nitrate of the operons encoding the [NiFe] hydrogenases 1 and 2 of Escherichia coli. Microbiology 145(Pt 10), 2903-2912. doi: 10.1099/00221287-14510-2903

Rupakula, A., Kruse, T., Boeren, S., Holliger, C., Smidt, H., and Maillard, J. (2013). The restricted metabolism of the obligate organohalide respiring bacterium Dehalobacter restrictus: lessons from tiered functional genomics. Philos. Trans. R. Soc. Lond. B Biol. Sci. 368, 20120325. doi: 10.1098/rstb.2012. 0325

Sargent, F. (2016). The model [NiFe]-hydrogenases of Escherichia coli. Adv. Microb. Physiol. 68, 433-507. doi: 10.1016/bs.ampbs.2016.02.008

Schmittgen, T. D., and Livak, K. J. (2008). Analyzing real-time PCR data by the comparative C(T) method. Nat. Protoc. 3, 1101-1108. doi: 10.1038/nprot. 2008.73

Scholz-Muramatsu, H., Neumann, A., Messmer, M., Moore, E., and Dieker, G. (1995). Isolation and characterization of Dehalospirillum multivorans gen. nov., sp. nov., a tetrachloroethene-utilizing, strictly anaerobic bacterium. Arch. Microbiol. 163, 48-56. doi: 10.1007/BF00262203

Seshadri, R., Adrian, L., Fouts, D. E., Eisen, J. A., Phillippy, A. M., Methe, B. A., et al. (2005). Genome sequence of the PCE-dechlorinating bacterium Dehalococcoides ethenogenes. Science 307, 105-108. doi: 10.1126/science. 1102226

Soboh, B., Linder, D., and Hedderich, R. (2002). Purification and catalytic properties of a CO-oxidizing:H2-evolving enzyme complex from Carboxydothermus hydrogenoformans. Eur. J. Biochem. 269, 5712-5721. doi: 10.1046/j.1432-1033.2002.03282.x
Stiebritz, M., and Reiher, M. (2012). Hydrogenases and oxygen. Chem. Sci. 3, 1739-1751. doi: 10.1039/c2sc01112c

Tamagnini, P., Leitão, E., Oliveira, P., Ferreira, D., Pinto, F., Harris, D. J., et al. (2007). Cyanobacterial hydrogenases: diversity, regulation and applications. FEMS Microbiol. Rev. 31, 692-720. doi: 10.1111/j.1574-6976.2007.00085.x

Tan, B., and Foght, J. (2014). Draft genome sequences of Campylobacterales (Epsilonproteobacteria) obtained from methanogenic oil sands tailings pond metagenomes. Genome Announc. 2:e1034-14. doi: 10.1128/genomeA.01034- 14

Trchounian, K., Poladyan, A., Vassilian, A., and Trchounian, A. (2012). Multiple and reversible hydrogenases for hydrogen production by Escherichia coli: dependence on fermentation substrate, $\mathrm{pH}$ and the $\mathrm{F}(0) \mathrm{F}(1)$-ATPase. Crit. Rev. Biochem. Mol. Biol. 47, 236-249. doi: 10.3109/10409238.2012.655375

Vetriani, C., Tran, H. V., and Kerkhof, L. J. (2003). Fingerprinting microbial assemblages from the oxic/anoxic chemocline of the Black Sea. Appl. Environ. Microbiol. 69, 6481-6488. doi: 10.1128/AEM.69.11.6481-6488.2003

Vignais, P. M., and Billoud, B. (2007). Occurrence, classification, and biological function of hydrogenases: an overview. Chem. Rev. 107, 4206-4272. doi: $10.1021 / \mathrm{cr} 050196 \mathrm{r}$

Villemur, R., Lanthier, M., Beaudet, R., and Lepine, F. (2006). The Desulfitobacterium genus. FEMS Microbiol. Rev. 30, 706-733. doi: 10.1111/j.1574-6976.2006.00029.x

Volbeda, A., Darnault, C., Parkin, A., Sargent, F., Armstrong, F. A., and FontecillaCamps, J. C. (2013). Crystal structure of the $\mathrm{O}(2)$-tolerant membrane-bound hydrogenase 1 from Escherichia coli in complex with its cognate cytochrome b. Structure 21, 184-190. doi: 10.1016/j.str.2012.11.010

Welte, C., Kratzer, C., and Deppenmeier, U. (2010). Involvement of Ech hydrogenase in energy conservation of Methanosarcina mazei. FEBS J. 277, 3396-3403. doi: 10.1111/j.1742-4658.2010.07744.x

Wulff, P., Thomas, C., Sargent, F., and Armstrong, F. A. (2016). How the oxygen tolerance of a $[\mathrm{NiFe}]-$ hydrogenase depends on quaternary structure. J. Biol. Inorg. Chem. 21, 121-134. doi: 10.1007/s00775-015-1327-6

Yoon, K. S., Tsukada, N., Sakai, Y., Ishii, M., Igarashi, Y., and Nishihara, H. (2008). Isolation and characterization of a new facultatively autotrophic hydrogenoxidizing Betaproteobacterium, Hydrogenophaga sp. AH-24. FEMS Microbiol. Lett. 278, 94-100. doi: 10.1111/j.1574-6968.2007.00983.x

Conflict of Interest Statement: The authors declare that the research was conducted in the absence of any commercial or financial relationships that could be construed as a potential conflict of interest.

Copyright (c) 2017 Kruse, Goris, Wolf, Wei and Diekert. This is an open-access article distributed under the terms of the Creative Commons Attribution License (CC BY). The use, distribution or reproduction in other forums is permitted, provided the original author(s) or licensor are credited and that the original publication in this journal is cited, in accordance with accepted academic practice. No use, distribution or reproduction is permitted which does not comply with these terms. 